\title{
Aortic aneurysm surgery: problems and innovations
}

\author{
Cirurgia do aneurisma aórtico: problemas e inovações \\ Ralf Kolvenbach ${ }^{1}$, Winston Bonetti Yoshida ${ }^{2}$
}

\begin{abstract}
A long way was traveled since the first surgery was performed for the treatment of abdominal aortic aneurysm. Throughout this time, several innovations have been created in order to reduce the invasiveness of the surgical procedures and to improve their safety and durability. This review discusses the major and recent advances on aortic aneurysm interventions, including, the endovascular aortic repair, the laparoscopic aortic surgery, the conventional hybrid and endovascular techniques, combined laparoscopic and endovascular techniques, as well as future prospects for both thoracic and abdominal aorta. Faced with so many changes and developments, modern vascular surgeons must keep their minds open to innovations and should develop comprehensive training with different techniques, to provide the best therapeutic option for their patients.
\end{abstract}

Keywords: Aneurysm, aorta, video-assisted surgery, blood vessel prosthesis implantation.

\section{Introduction}

Over the past 50 years, enormous progress has been made in aortic reconstructions.

Major operations have been reduced to routine procedures via groin punctures or cut downs. In 1991, endovascular aneurysm exclusion was introduced by Parodi provoking strong opposition from the vascular surgical community. ${ }^{1}$ Since then, we have gathered a huge amount of data regarding indication and techniques for endovascular aneurysm repair. We now have different endografts with special designs for the abdominal and thoracic aorta. The term "transluminal placement of endograft" was introduced in 1994 by Frank Veith. ${ }^{2}$ He defined a technology where a prosthetic conduit was inserted via a remote access, guided within a blood vessel to repair the vascular disease in a less invasive fashion than would characterize the standard operative approach.

New techniques and methods are associated with new complications, which can easily get us to the limits of in-

\section{Resumo}

Um longo caminho foi percorrido desde as primeiras intervenções cirúrgicas feitas para o tratamento do aneurisma de aorta abdominal. Ao longo deste tempo, várias inovações foram criadas, no sentido de reduzir a invasividade dos procedimentos e melhorar sua segurança e durabilidade. Nesta revisão, são discutidos os principais e recentes avanços em intervenções sobre aneurismas aórticos, incluindo a restauração aórtica endovascular, a cirurgia aórtica videolaparoscópica, as técnicas híbridas convencionais e endovasculares, as técnicas combinadas videolaparoscópicas e endovasculares, bem como as perspectivas futuras, tanto para aorta torácica como abdominal. Diante de tantas transformações e evolução, o cirurgião vascular moderno terá que ter sua mente aberta para as novidades e desenvolver capacitação ampla com diferentes técnicas para proporcionar a melhor opção terapêutica para seus pacientes.

Palavras-chave: Aneurisma, aorta, cirurgia videoassistida, implante de prótese vascular.

novative surgical procedures. Endografts do not have the same performance characteristics in the descending aorta compared to abdominal aortic aneurysms (AAA).

\section{Descending aortic aneurysms}

We have three- to five-year results of endografting of thoracic descending aortic aneurysms or acute and chronic type B dissections. Since these are mainly case control studies or simple case reports, there is still a lot of place for interpretation. Until today, we have a lack of controlled studies and long-term results. We still do not know whether in a case with acute type B dissection stent graft repair is really mandatory or rather an expensive overtreatment (Figures 1 and 2).

We do not have prospective randomized studies available for thoracic aneurysms. There are several studies showing that morbidity and mortality are significantly lower after endovascular aneurysm repair compared to open surgery. It seems that this is also true for neurological events, such as paraplegia.

1. MD, PhD. Augusta Hospital and Catholic Clinics, Düsseldorf, Germany.

2. MD, PhD. Department of Surgery and Orthopedics, Faculdade de Medicina de Botucatu, Universidade Estadual Paulista (UNESP), Botucatu, SP, Brazil.

No conflicts of interest declared concerning the publication of this article.

Manuscript received Apr 14 2009, accepted for publication Oct 292009.

J Vasc Bras. 2009;8(4):327-334.

Copyright (C 2009 by Sociedade Brasileira de Angiologia e de Cirurgia Vascular 
However, paraplegia can still occur in up to $4 \%$ of those patients stented for descending thoracic aortic aneurysms (TAA). Figure 3 shows a Crawford type II TAA with a widely patent great radicular artery of Adamkie-

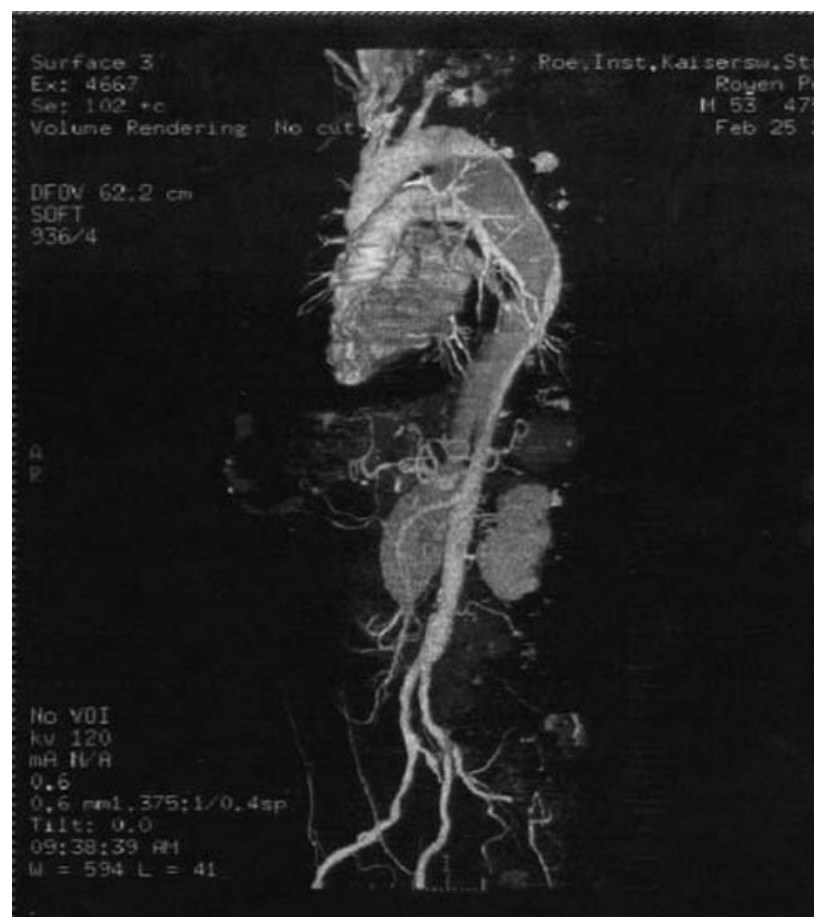

Figure 1 - Descending thoracic aortic aneurysm after type B dissection

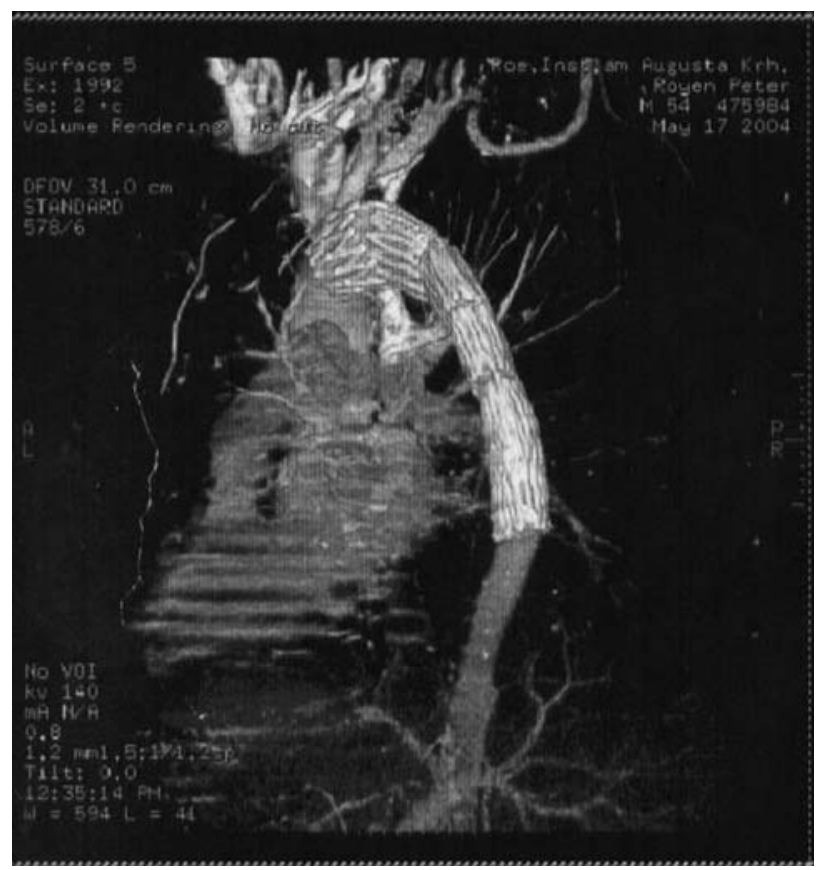

Figure 2 - Stent graft excludes aneurysm of the thoracic aorta wicz. The patient was operated using an open approach with reimplantation of the intercostals arteries. He had an uneventful recovery without any neurological problems.

\section{Abdominal aortic aneurysms}

Endovascular surgery is minimal invasive because of reduced access trauma. More importantly, we do not have prolonged ischemia times with subsequent ischemia/reperfusion injury. Yet we still have severe complications including graft migration and rupture. Therefore we owe it to our patients to discuss the pros and cons of the minimal invasive procedure critically. Patients with large aneurysms $(>5.5 \mathrm{~cm})$ do have a higher incidence of rupture than patients with smaller aneurysms $(<5.5 \mathrm{~cm})$ : $6.1 \mathrm{vs}$. $1.5 \%$. This must be discussed when considering the spontaneous course of small aneurysms. ${ }^{3,4}$ According to the U.K. Small Aneurysm Trial, ${ }^{5}$ the incidence of rupture is less than $1 \%$ per year in aneurysms $<5.5 \mathrm{~cm}$. Therefore the cost/benefit ratio must be taken into account when presenting treatment options to aneurysm patients. Yet morphology of small aneurysms is much more favorable for an

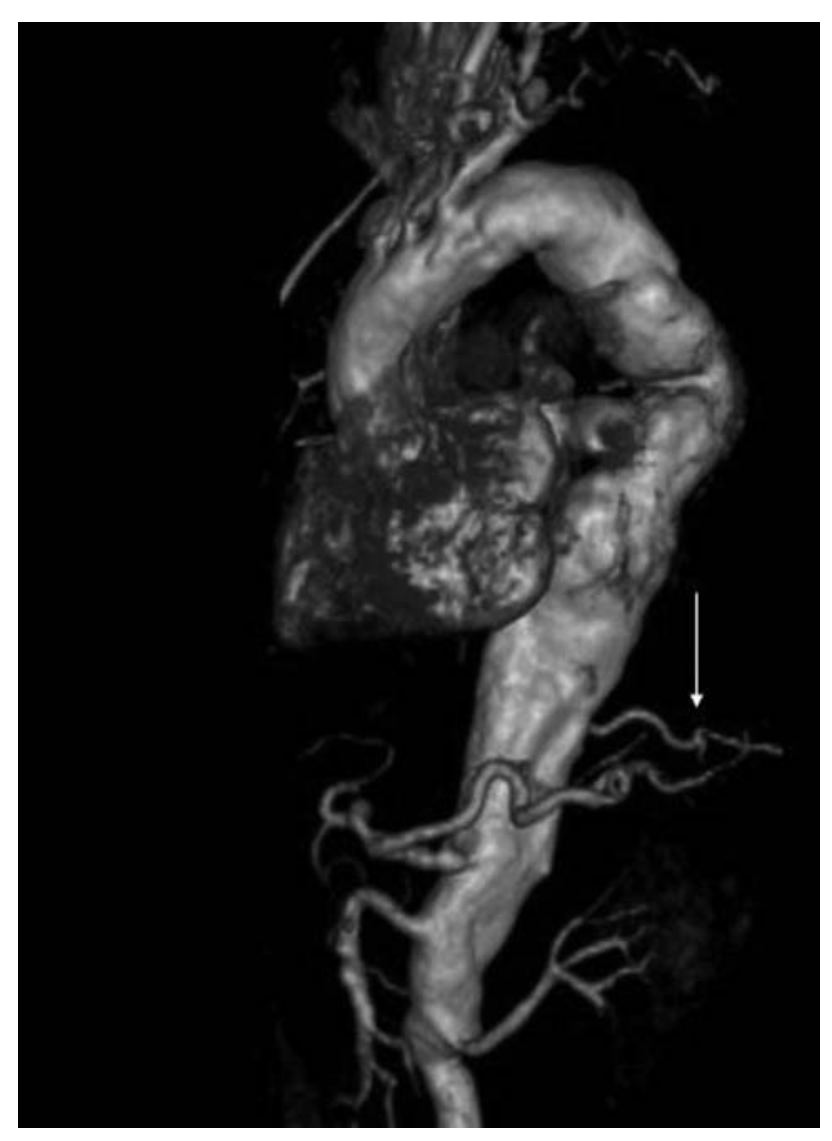

Figure 3 - Preoperative angio-CT scan with intercostal artery 
endovascular procedure in small AAA than in large aortic aneurysms. Ongoing prospective randomized studies will show whether prophylactic stenting will be a treatment option. This idea will certainly not be shared by most health care providers.

A major problem is the cost associated with endovascular aneurysm repair. Probably this is one reason why the authors of the Endovascular Aortic Repair (EVAR)-1Study conclude that EVAR should only be introduced into daily clinical practice when long-term results will become available. ${ }^{3,4}$

Aortic morphology is critical in determining the successful outcome of EVAR. Inadequate proximal aortic neck is most often the criteria for exclusion of EVAR. ${ }^{6} \mathrm{~Pa}-$ tients with short, heavily calcified aneurismal neck and large aneurysm are at increased risk of proximal type I endoleaks and an ongoing risk of rupture. Endografting of AAA in patients with complicated neck anatomy is associated with a greater incidence of adverse renal events. Because difficult aortic neck morphology is associated with increased device migration, type I and II endoleaks, and renal insufficiency, it compromises the successful outcome of EVAR.

\section{Hybrid techniques}

A lot of patients, especially with large aneurysms do not have an adequate landing zone. In these cases, either conventional surgery is required or fenestrated or branched grafts can be used. Both techniques, taking in account their short-term results, are still considered to be more or less experimental. There is still a significant incidence of thrombosis of the renal or visceral branches with severe consequences which include the complete loss of a originally well functioning kidney. Alternatively, so called hybrid techniques can be used. This simply means a combination of conventional bypass surgery and endovascular therapy. Patients with thoracoabdominal aneurysms can be treated with an endovascular graft in combination with multiple bypasses to the visceral and renal arteries (Figures 4 and 5). With this hybrid technique there is no need for a thoracotomy with a subsequent smoother postoperative course and reduced ischemia time.

Hybrid techniques can also be used as a less invasive alternative for aortic arch repair (Figure 6). The technique is associated with debranching of the supra-aortic vessels
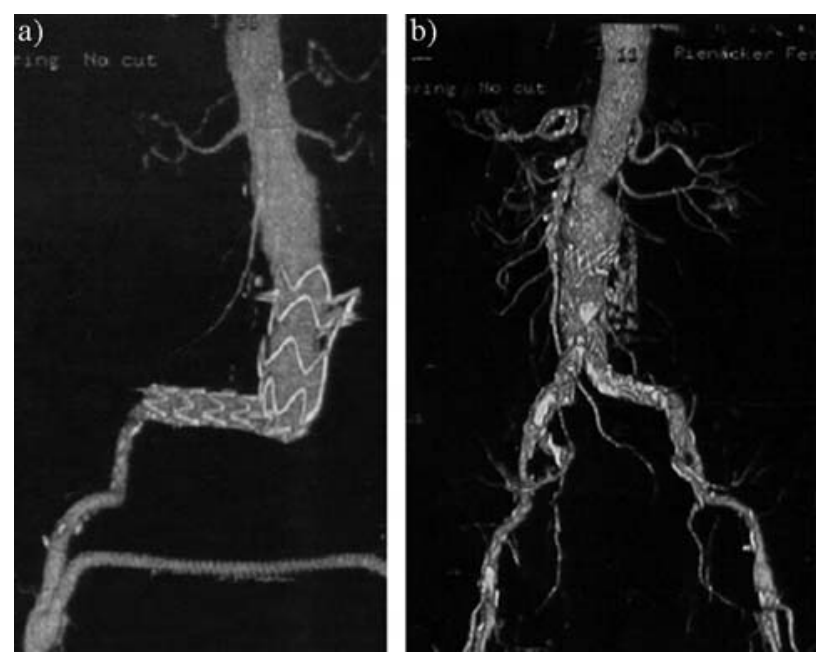

Figure 4 - Complete debranching of the visceral and the renal arteries: A) ilio-renal bypass originating from the right iliac artery; B) modified bifurcated graft revascularizes the left renal artery and the visceral vessels

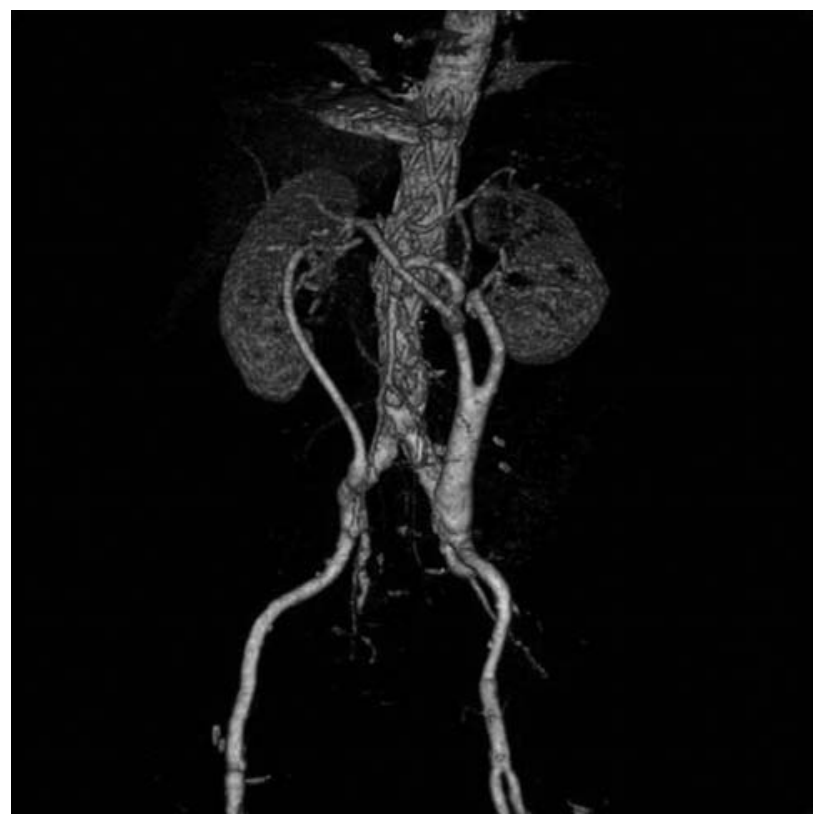

Figure 5 - Increased landing zone after aorto-hepatic bypass to permit overstenting of the celiac trunk

without any need for cardiopulmonary bypass, thus reducing the incidence of cerebral complications. Considering the significant morbidity and mortality with neurological problems between 12 and $40 \%$ after conventional aortic arch repair, we can see that here is still a lot of place for improvement and definitely a role for less invasive endovascular procedures. In contrast to other authors, we do not believe that routine covering of the origin of the left sub- 


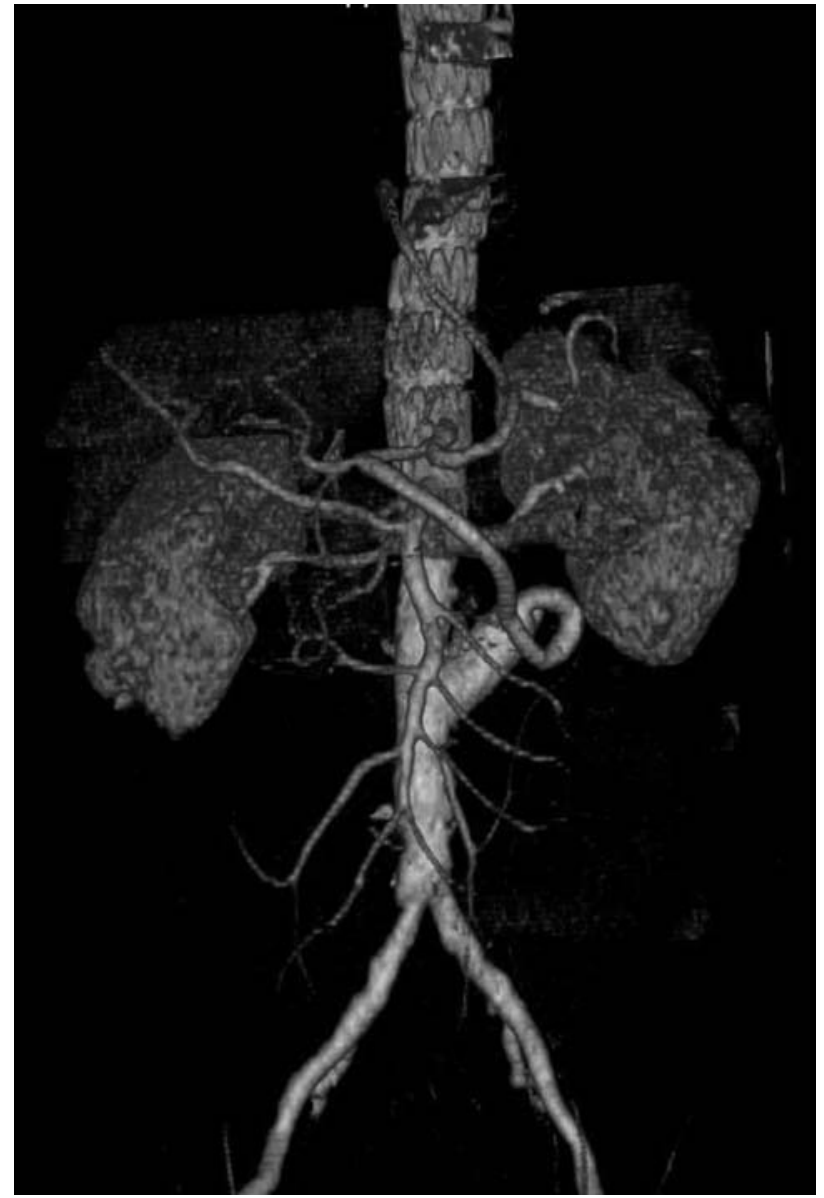

Figure 6 - Aortic arch saccular aneurysm suitable for debranching surgery

clavian artery is advisable. There are some anecdotal data that this can increase the incidence of paraplegia after endografting of the descending thoracic aorta by shutting off the internal thoracic artery as a collateral pathway. Offpump vascular surgery can only be performed in close collaboration between vascular surgeons, radiologists, and anesthetists.

\section{The role of EVAR today}

There is no doubt that endovascular aortic surgery is becoming the first line of treatment in patients with aortic disease and even in ruptured aneurysms. ${ }^{7-9}$ Though in ruptured cases there is quite often no adequate proximal landing zone because of the diameter of the infrarenal aorta.

Since there is a lot enthusiasm from patients and from medical device manufacturers we can be sure that endovascular aneurysm exclusion is here to stay irrespective of recent studies and publications. ${ }^{10-16}$ Principally, a patient who today is well informed has the right to select less proven but minimally invasive, cutting-edge technology with fewer immediate risks even if conventional open surgery is more established and obviously more durable. The need for repeat interventions because of early failure appears to be less of a problem for many patients than previously thought, as long as the procedure poses minimal risk. Open vascular surgery is still needed in almost all areas of vascular surgery. This is supported by level 1 evidence provided by recently published prospective randomized multicenter studies. The British clinical trial EVAR-1 found no survival difference at 4 years between open and endovascular repair of AAA. The EVAR-2 trial found no advantage of stent grafts over observation in high risk patients who underwent endovascular aneurysm repair, and the smaller Dutch DREAM trial also failed to find survival difference at 3 years between those who underwent endovascular treatment and those who had open surgical repair. ${ }^{3,4}$ In addition, it will be another 4 years when the PIVOTAL study is completed, until we find out whether endovascular repair is justified in patients with small aortic aneurysms. Even enthusiastic proponents of endovascular therapy admit that 6 years from now, there will still be plenty of open vascular surgery.

\section{Laparoscopic aortic surgery}

In a number of centers, especially in Canada, France, Italy and some other European countries, laparoscopic aortic surgery emerged as the third less invasive way. ${ }^{17-28}$ Like in any other laparoscopic procedures, we have a reduced access trauma, but we still have the problem of ische$\mathrm{mia} /$ reperfusion injury due to aortic clamping times which are still longer compared to open surgery. It may be expected that the outcome of laparoscopic resection for instance of AAA is equivalent to the gold standards, a transperitoneal tube graft repair, simply because the conventional operation is performed laparoscopically. Total laparoscopic aortic procedures can be performed in patients with occlusive disease, as well as in aneurysm cases. Basic principle of a total laparoscopic operation is that the anastomosis is performed with laparoscopic needle holders under pneumoperitoneum.

Basically, we can implement laparoscopic techniques in three ways in aortic surgery. 
First is laparoscopic exposure of the retroperitoneum and the aorta. Subsequently, a mini laparotomy is performed to suture the aortic graft to the aorta. This is a very straight forward and relatively easy technique, because it avoids the need for laparoscopic suturing.

Second there are technically more demanding total laparoscopic procedures where the whole operation is performed under pneumoperitoneum and third the so-called hybrid techniques.

\section{Combining laparoscopy and EVAR}

Hybrid techniques means that after insertion of the stent graft to exclude the aneurysm, laparoscopy is performed to secure the stent graft in the region of a short infrarenal neck with a band or sutures and to clip lumbar arteries and the inferior mesenteric artery to avoid type 2 endoleaks. Despite encouraging short and mid-term results, problems such as endoleaks, endotension and graft migration are frequently encountered after EVAR. ${ }^{29-31}$ With close follow-up, re-interventions after EVAR reveal a significant number of secondary procedures between 10 to $27 \%$ and an annual rate of late rupture at 0.5 to $1.5 \%$. Without intervention, persistent endoleaks are associated with late aneurysm rupture and the subsequent, long-term failure of EVAR. ${ }^{32-36}$ Laparoscopic techniques can be used to overcome many of these challenges after EVAR. Laparoscopic adjuncts after EVAR include several options: 1) clipping of the inferior mesenteric artery (IMA) and lumbar arteries to treat type II endoleaks; 2) thrombus removal and tight closure of the sac of the aneurysm to reduce the sac diameter; 3) fixation of the endograft to the aortic neck to prevent device migration; 4) banding of the aorta to prevent neck dilatation and; 5) laparoscopic conversion after EVAR failure (Figure 7).

Hybrid procedure aims to prevent the three of the complications after EVAR using laparoscopic techniques. First of all, laparoscopic clipping of the IMA and lumbar arteries is an effective method to treat patients with type II endoleaks following EVAR. Because we dissect the aorta from the left side, clipping of the left lumbar arteries is readily accessible and technically easier than the right. Endovascular coiling of patent lumbar arteries or IMA is another possibility for the treatment of type II endoleaks; however, endovascular technique is successful in only $65 \%$ of the patients. ${ }^{37,38}$ A substantial number of patients

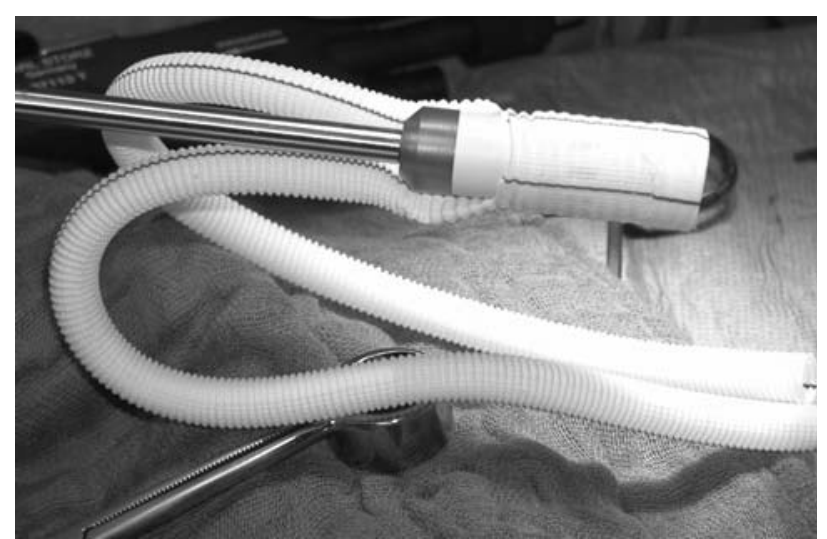

Figure 7 - Aorto-monoiliac Talent ${ }^{\circledR}$ stent graft which has migrated completely into the sac of the aneurysm; since endovascular repair with an extension cuff was impossible, laparoscopic conversion was performed

with endotension and aneurysm sac expansion after EVAR have been found without any evidence of patent lumbar or inferior mesenteric arteries. We are able to identify patent lumbar arteries on laparoscopy that were not evident on CT scan or angiography. However, controversy still exists regarding the treatment of type II endoleaks because the indication is not absolutely well-defined. ${ }^{39}$

Secondly, the major advantage of laparoscopic clipping is that other adjunctive procedures could be done at the same time, such as sactomy with thrombus removal and tight closure of the aneurysm sac. This significant reduction in sac diameter is observed immediately after the laparoscopic procedure and continues to stabilize during the serial follow-up CT scan (Table 1). It is thought that macrophages can generate free oxygen radicals in the canaliculi of the intraluminal thrombus, which causes further degeneration of the aortic wall by enhancing tissue hypoxia. Thrombus transmits pressure that can explain the presence of endotension and sac enlargement in the absence

Table 1 - Perioperative and operative parameters of hybrid procedures

\begin{tabular}{lcc}
\hline Complicated aortic neck & $19(100 \%)$ & $4(36.3 \%)$ \\
\hline Preoperative AAA diameter $(\mathrm{mm})$ & $63 \pm 6$ & $61 \pm 9$ \\
Postoperative sac diameter (mm) & $40 \pm 10$ & $34 \pm 7$ \\
Period of follow-up (months) & $9.2 \pm 4.8$ & $11.5 \pm 6.6$ \\
\hline
\end{tabular}

$\mathrm{AAA}=$ abdominal aortic aneurysms.

There is a significant reduction of the diameter of abdominal aortic aneurysms after laparoscopic downsizing. 
of type II endoleaks. Theoretically, evacuation of thrombus could destabilize the endograft and weaken the outer shell of the aneurysm. However, we hope that wrapping of the sac around the endograft, similar to a Creech procedure, will accelerate the graft incorporation and aneurysm sac reduction. Thirdly, proximal fixation of endograft is of critical importance in determining the successful outcome of EVAR. In a study of Talent stent-grafts for patients with large infrarenal aortic neck, $17.5 \%$ of the devices exhibited distal migration during a 17 -month follow-up. ${ }^{40,41}$ Better fixation and banding of the endograft to the aorta could prevent device migration and reduce aortic neck dilatation, respectively. ${ }^{42}$ Using special suturing techniques, the endoprosthesis is secured to the aortic wall. This may be combined with a banding procedure to enlarge the landing zone and to prevent neck dilatation.

So-called hybrid techniques can also be used in more complex aneurysms involving the suprarenal aorta or in thoracoabdominal aortic aneurysms. In these cases, aortic debranching is performed laparoscopically with the help of a mini-incision. Subsequently, the aneurysm is excluded with stent grafts. This avoids the need for cost expensive branched grafts probably offering to the patients a more durable alternative with less long-term complications. One problem is that only younger vascular surgeons have been trained in laparoscopic techniques and many older vascular surgeons who have merely acquired the necessary endovascular skills lack any video-endoscopic exposure and training. This is associated with a certain fear to adopt once again a completely new technique. Another even more important factor is the quite cumbersome total laparoscopic anastomosis after successful exposure of the aorta.

\section{Future perspectives}

In the near future vascular stapling devices will be on the market, which similar to colorectal surgery, have a potential to replace a hand-sawn anastomosis. Stapling technology will also permit endovascular exclusion of aneurysms with a short neck preventing graft migration and subsequent conversion to open surgery.

With stapling technology on the horizon, it should be possible to reduce clamping time in open surgery to a few minutes (Figure 8).

Robotic surgery is also trying to find a place in laparoscopic procedures $-\mathrm{a}$ tool looking for an application as

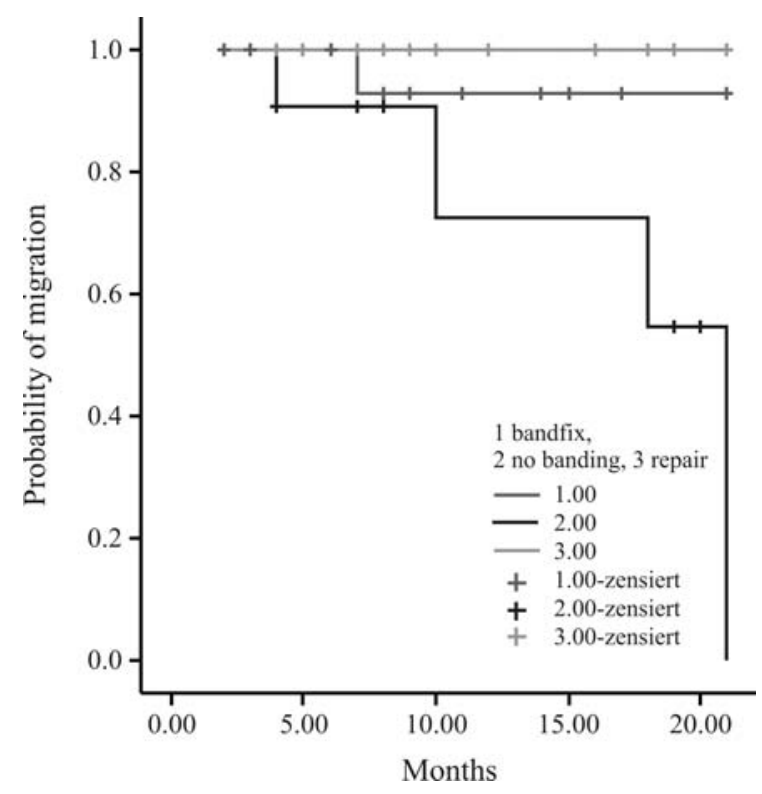

Figure 8 - Laparoscopic aortic stapler with bifurcated graft: a horizon to reduce clamping time in open surgery

was recently outlined in an editorial. ${ }^{43}$ The Da Vinci robot has already been used in several centers to perform aortofemoral bypass surgery. The device is mainly used for suturing the protheto-aortic anastomosis rather than merely as a dissection tool. A surgical robot is actually a collection of wristed "servant" tools called manipulators, which receive digital instructions from an interfaced computer. The "master" surgeon, seated at an ergonomically designed video console with an "immersive" three-dimensional display, initiates the digital instructions by controlling sophisticated hand grips - essentially, joysticks with seven degrees of freedom. ${ }^{43}$

Costs are a more than essential issue. A robot can cost US\$1 million or more, not including the maintenance contract and the expensive disposable items required for each procedure. Its instruments do not provide a sense of touch. The learning curve for the effective use of these tools is long and steep. The robot's toolbox is not very full, and the time required to switch from one instrument to another lengthens operating time. Most of all, the majority of published studies of robot-assisted surgery have really been technical notes describing feasibility. Prospective studies comparing robotic with conventional procedures will be needed in order to establish a clear benefit. ${ }^{43}$

Pharmacological treatment particularly of small aneurysms might soon present another promising treatment 
option. ${ }^{44}$ The degradation of extracellular-matrix proteins elastin and collagen in the aortic wall is critical to the pathogenesis of aortic aneurysms. A process which in part can be inhibited by administering the antibiotic amoxicillin yet with all the side effects of a long-term antibiotic treatment. The metallo-proteinases 2.8 and 9 have been identified as crucial in the degradation of elastin. A recent experimental study indicates that inhibition of the stress-activated protein kinase, Jun N-terminal kinase (JNK) can effectively prevent aneurysm growth and can cause even regression of already existing aneurysms. ${ }^{45}$

\section{Conclusion}

In conclusion, these days we see radical changes how aortic aneurysms are treated in daily clinical practice. Since the first aneurysm resection by Dubost only few changes could be observed over a period of more than 30 years. This is now changing rapidly. The only question will be whether vascular surgeons will be among those who will determine which treatment option will be chosen for our patients. This requires an open mind for innovative evolving therapies.

\section{References}

1. Parodi JC, Palmaz JC, Barone HD. Transfemoral intraluminal graft implantation for abdominal aortic aneurysms. Ann Vasc Surg. 1991;5:491-9.

2. Veith FJ. Transluminally placed endovascular stented grafts and their impact on vascular surgery. J Vasc Surg. 1994;20:855-60.

3. EVAR Trial participants. Endovascular aneurysm repair versus open repair in patients with abdominal aortic aneurysms (EVAR trial 1): randomised controlled trial. Lancet. 2005;365:2179-86.

4. Blankensteijn JD, Jong SE, Prinssen M, et al. Two-year outcomes after conventional or endovascular repair of abdominal aortic aneurysms. N Engl J Med. 2005;352:2398-405.

5. Schermerhorn ML, Cronenwett JL. The UK small aneurysm trial. J Vasc Surg. 2001;33:443.

6. DeVirgilio C, Bui H, Donayre C, et al. Endovascular vs open abdominal aortic aneurysm repair. a comparison of cardiac morbidity and mortality. Arch Surg. 1999;134:947-50; discussion 950-1.

7. Beebe HG, Cronenwett JL, Katzen BT, Brewster DC, Green RM; Vanguard Endograft Trial Investigators. Results of an aortic endograft trial: impact of device failure beyond 12 months. J Vasc Surg. 2001;33:S55-63.

8. Zarins CK, Arko FR, Lee WA, et al. Effectiveness of endovascular versus open repair in prevention of aneurysm related death. In: Proceedings of the 49th Scientific Meeting of the American Association for Vascular Surgery; 2001; Baltimore, MD, USA.
9. Zarins CK, Arko FR, Lee WA, et al. Effectiveness of endovascular versus open repair in prevention of aneurysm related death. In: Proceedings of the 49th Scientific Meeting of the American Association for Vascular Surgery; 2001; Baltimore, MD, USA.

10. Harris PL, Vallabhaneni SR, Desgranges P, Becquemin JP, van Marrewijk C, Laheij RJ. Incidence and risk factors of late rupture, conversion, and death after endovascular repair of infrarenal aortic aneurysms: the EUROSTAR experience. J Vasc Surg. 2000;32:739-49.

11. White GH, Yu W, May J, et al. Endoleaks as a complication of endoluminal grafting of abdominal aortic aneurysm: classification, incidence, diagnosis, and management. J Endovasc Surg. 1997;4:152-68.

12. Veith FJ, Baum RA, Ohki T, et al. Nature and significance of endoleaks and endotension: summary of opinions expressed at an international conference. J Vasc Surg. 2002;35:1029-35.

13. Matsumura JS, Moore WS. Clinical consequences of periprosthetic leak after endovascular repair of abdominal aortic aneurysm. J Vasc Surg. 1998;27:606-13.

14. Sonesson B, Malina M, Ivancev K, Lindh M, Lindblad B, Brunkwall J. Dilatation of the infrarenal aneurysm neck after endovascular exclusion of abdominal aortic aneurysm. J Endovasc Surg. 1998;5:195-200.

15. Zarins CK, White RA, Fogarty TJ. Aneurysm rupture after endovascular repair using the AneuRx stent graft. J Vasc Surg. 2000;31:960-70.

16. Schlensak C, Doenst T, Hauer M, et al. Serious complications that require surgical interventions after endoluminal stent-graft placement for the treatment of infrarenal aortic aneurysms. J Vasc Surg. 2001;34:198-203.

17. Dion YM, Gracia CR, El Kadi HH. Totally laparoscopic abdominal aortic aneurysm repair. J Vasc Surg. 2001;33:181-5.

18. Coggia M, Bourriez A, Javerliat I, Goeau-Brissonniere O. Totally laparoscopic aortobifemoral bypass: a new and simplified approach. Eur J Vasc Endovasc Surg. 2002;24:274-5.

19. Da Silva L, Kolvenbach R, Pinter L. The feasibility of handassisted laparoscopic bypass using a low transverse incision. Surg Endosc. 2002;16:173-6.

20. Kolvenbach R, Ceshire N, Pinter L, Da Silva L, Deling O, Kasper AS. Laparoscopy-assisted aneurysm resection as a minimal invasive alternative in patients unsuitable for endovascular surgery. J Vasc Surg. 2001;34:216-21.

21. Wisselink W, Cuesta M, Gracia C, Rauwerda J. Robotassisted laparoscopic aortobifemoral bypass for aortoiliac occlusive disease: a report of two cases. J Vasc Surg. 2002;36:1079-82.

22. Kolvenbach R, Schwierz E. Combined endovascular / laparoscopic approach to aortic pseudoaneurysm repair. J Endovasc Surg. 1998;5:191-3.

23. Kolvenbach R, Pinter L, Raghunandan M, Cheshire N, Ramadan H, Dion YM. Laparoscopic remodeling of abdominal aortic aneurysms after endovascular exclusion: a technical description. J Vasc Surg. 2002;36:1267-70.

24. Alimi YS, Di Molfetta L, Hartung O, et al. Laparoscopyassisted abdominal aortic aneurysm endoaneurysmorraphy: early and mid-term results. J Vasc Surg. 2003;37:744-9. 
25. Kolvenbach R, Da Silva L, Deling O, Schwierz E. Videoassisted aortic surgery. J Am Coll Surg. 2000;190:451-7.

26. Kolvenbach R, Deling O, Schwierz E, Landers B. Reducing the operative trauma in aortoiliac reconstructions - a prospective study to evaluate the role of video-assisted vascular surgery. Euro J Vasc Endovasc Surg. 1998;15:483-8.

27. Lin JC, Kolvenbach R, Wassiljew S, Pinter L, Schwierz E, Puerschel A. Totally laparoscopic explantation of migrated stent graft after endovascular aneurysm repair: a report of two cases. J Vasc Surg. 2005;41:885-8.

28. Kolvenbach R, Schwierz E, Wasilljew S, Miloud A, Puerschel A, Pinter L. Total laparoscopically and robotically assisted aortic aneurysm surgery: a critical evaluation. J Vasc Surg. 2004;39:771-6.

29. Laheij RJ, Buth J, Harris PL, Moll FL, Stelter WJ, Verhoeven EL. Need for secondary interventions after endovascular repair of abdominal aortic aneurysms. Intermediate-term follow-up results of a European collaborative registry (EUROSTAR). Br J Surg. 2000;87:1666-73.

30. Patterson MA, Jean-Claude JM, Crain MR, et al. Lessons learned in adopting endovascular techniques for treating abdominal aortic aneurysm. Arch Surg. 2001;136:627-34.

31. Conner MS 3rd, Sternbergh WC 3rd, Carter G, Tonnessen $\mathrm{BH}$, Yoselevitz M, Money SR. Secondary procedures after endovascular aortic aneurysm repair. J Vasc Surg. 2002;36:992-6.

32. Elkouri S, Gloviczki P, McKusick MA, et al. Perioperative complications and early outcome after endovascular and open surgical repair of abdominal aortic aneurysms. J Vasc Surg. 2004;39:497-505.

33. Harris PL, Vallabhaneni SR, Desgranges P, Becquemin JP, van Marrewijk C, Laheij RJ. Incidence and risk factors of late rupture, conversion, and death after endovascular repair of infrarenal aortic aneurysms: the EUROSTAR experience. European Collaborators on Stent/Graft Techniques for Aortic Aneurysm Repair. J Vasc Surg. 2000;32:739-49.

34. Fransen GA, Vallabhaneni SR Sr, van Marrewijk CJ, et al. Rupture of infra-renal aortic aneurysm after endovascular repair: a series from EUROSTAR registry. Eur J Vasc Endovasc Surg. 2003;26:487-93.

35. Ohki T, Veith FJ, Shaw P, et al. Increasing incidence of midterm and long-term complications after endovascular graft repair of abdominal aortic aneurysms: a note of caution based on a 9-year experience. Ann Surg. 2001;234:323-34.

36. Hölzenbein TJ, Kretschmer G, Thurnher S, et al. Midterm durability of abdominal aortic aneurysm endograft repair: a word of caution. J Vasc Surg. 2001;33:S46-54.

37. Becquemin JP, Kelley L, Zubilewicz T, Desgranges P, Lapeyre M, Kobeiter H. Outcomes of secondary interventions after abdominal aortic aneurysm endovascular repair. J Vasc Surg. 2004;39:298-305.

38. Hobo R, Buth J; EUROSTAR Collaborators. Secondary interventions following endovascular abdominal aortic aneu- rysm repair using current endografts. A EUROSTAR report. J Vasc Surg. 2006;43:896-902.

39. Elkouri S, Martelli E, Gloviczki P, et al. Most patients with abdominal aortic aneurysm are not suitable for endovascular repair using currently approved bifurcated stent-grafts. Vasc Endovasc Surg. 2004;38:401-12.

40. Sampaio SM, Panneton JM, Mozes GI, et al. Proximal type I endoleak after endovascular abdominal aortic aneurysm repair: predictive factors. Ann Vasc Surg. 2004;18:621-8.

41. Rockman CB, Lamparello PJ, Adelman MA, et al. Aneurysm morphology as a predictor of endoleak following endovascular aortic aneurysm repair: do smaller aneurysm have better outcomes? Ann Vasc Surg. 2002;16:644-51.

42. Fairman RM, Velazquez OC, Carpenter JP, et al. Midterm pivotal trial results of the Talent Low Profile System for repair of abdominal aortic aneurysm: analysis of complicated versus uncomplicated aortic necks. J Vasc Surg. 2004;40:1074-82.

43. Camarillo DB, Krummel TM, Salisbury JK Jr. Robotic technology in surgery: past, present, and future. Am J Surg. 2004; 188:2S-15S.

44. Verma S, Lindsay TF Regression of aortic aneurysms through pharmacologic therapy. $\mathrm{N}$ Engl J Med. 2006;354:2067-8.

45. Yoshimura K, Aoki H, Ikeda Y, et al. Regression of abdominal aortic aneurysm by inhibition of c-Jun $\mathrm{N}$-terminal kinase. Nat Med. 2005;11:1330-8.

Correspondence:

Prof. Ralf Kolvenbach, MD, PhD

Department of Vascular Surgery and Endovascular Therapy

Augusta Hospital and Union of Catholic Hospitals

Düsseldorf - Germany

Tel.: +49 (211) 904.3301

Fax: +49 (211) 904.3309

E-mail: kolvenbach@kmr-kliniken.de

\section{Author contributions}

Conception and design: RK

Analysis and interpretation: N/A

Data collection: RK

Writing the article: RK, WY

Critical revision of the article: RK, WY

Final approval of the article*: RK, WY

Statistical analysis: N/A

Overall responsibility: RK, WY

Obtained funding: N/A

* All authors have read and approved of the final version of the article submitted to J Vasc Bras. 